Alexander, D., Allardice, G. M., Moug, S. J. and Morrison, D. S. (2017) A retrospective cohort study of the influence of lifestyle factors on survival of patients undergoing surgery for colorectal cancer.

Colorectal Disease, 19(6), pp. 544-550. (doi:10.1111/codi.13594)

There may be differences between this version and the published version. You are advised to consult the publisher's version if you wish to cite from it.

This is the peer-reviewed version of the following article: Alexander, D., Allardice, G. M., Moug, S. J. and Morrison, D. S. (2017) A retrospective cohort study of the influence of lifestyle factors on survival of patients undergoing surgery for colorectal cancer. Colorectal Disease, 19(6), pp. 544-550, which has been published in final form at 10.1111/codi.13594. This article may be used for noncommercial purposes in accordance with Wiley Terms and Conditions for Self-Archiving.

http://eprints.gla.ac.uk/134453/

Deposited on: 07 February 2017

Enlighten - Research publications by members of the University of Glasgow http://eprints.gla.ac.uk 


\section{A retrospective cohort study of the influence of lifestyle factors on survival of patients undergoing surgery for colorectal cancer}

Dayna Alexander ${ }^{1}$, Gwen M Allardice², Susan J Moug ${ }^{3}$ * , David S Morrison ${ }^{4}$.

1 Undergraduate Medical Student, University of Glasgow, University Avenue, Glasgow G12 8QQ. 1007951A@student.gla.ac.uk

2 Statistician, West of Scotland Cancer Surveillance Unit, Glasgow G12 8RZ. Gwen.Allardice@glasgow.ac.uk

3 *Corresponding author. PhD, FRCS. Consultant Colorectal Surgeon, Department of Surgery, Royal Alexandra Hospital, Paisley, Corsebar Road, PA2 9PN. ++44-141-314-6965. susanmoug@nhs.net

4 MRCPI, MPH, FFPH, MD. Consultant in Public Health Medicine, West of Scotland Cancer Surveillance Unit, Glasgow G12 8RZ. David.Morrison@glasgow.ac.uk

No funding was required for this work. The authors declare no conflicts of interest. 
Authors' contributions

SM \& DM led the development and design of the study.

DA led the research and wrote the first draft of the paper under the supervision of DM \& SM

DA \& GA shared in the analyses of the data

GA and SM led the final submission

All authors contributed to the manuscript preparation. All authors read and approved the final manuscript.

Acknowledgements

The authors acknowledge the help of B Sloan in providing IT support and P McLoone in providing statistical advice.

\section{Abstract}

Aim: Several modifiable and non-modifiable health related behaviours are associated with the incidence of Colorectal Cancer (CRC), but there is little research on their association with survival. The project aimed to investigate possible relationships between modifiable behavioural factors and outcomes on a study cohort of CRC patients undergoing potentially curative surgery.

Method: A retrospective cohort study was carried out of patients diagnosed with non-metastatic CRC undergoing elective curative surgery (January 2011 - December 2012), residing in the NHS Greater Glasgow \& Clyde (NHSGGC) area, UK. Data were obtained from the Scottish Cancer Registry, National Scottish Death Records. Pre-operative assessment of smoking, alcohol consumption, nurse-measured body mass index (BMI) and exercise levels were recorded and patients were followed until death or censorship. Survival analysis was carried out and 
proportional hazards assumptions were assessed graphically using plots and were then formally tested using the PHTEST procedure in STATA.

Results: Of the initial 527 patients, 181 (34\%) satisfied the inclusion criteria. The total duration of follow up was 480 person-years. At the pre-operative assessment, $75 \%$ were overweight or obese, $10.6 \%$ were current smokers, $13.1 \%$ recorded excess alcohol consumption and $8.5 \%$ had physical difficulty climbing stairs. Age, BMI, histopathological stage and physical capacity all independently affected survival $(P<0.05)$. Overweight patients (HR 2.81) and those who had difficulty climbing stairs (HR 3.31) had a significantly poorer survival.

Conclusion: The study found evidence that pre-operative exercise capacity and BMI are important independent prognostic factors of survival in patients undergoing curative surgery for CRC.

\section{What does this paper add to the literature?}

There is strong evidence for associations between lifestyle factors and the incidence of colorectal cancer, yet there is little information on their possible effect on long-term outcomes. This paper found pre-operative physical capacity and body mass index to be independent prognostic factors for survival in patients undergoing curative surgery for CRC.

\section{Introduction}

Colorectal cancer (CRC) is the third most common cancer world wide and the second most frequent cause of cancer related death world wide[1, 2]. Approximately 1,600 people die from colorectal disease in Scotland each year, the highest rate in the western world ${ }^{1}$. High rates of unhealthy lifestyle behaviours and the poor prognosis of many patients with CRC make it a major public health concern in Scotland $[1,3]$. 
There are many known causal factors for CRC. Some are modifiable, such as diet, smoking, body weight and physical activity and others are not such as age, family history and inflammatory bowel disease ${ }^{1}$. With the increasing incidence of the disease and decreasing mortality, the number of survivors after treatment of CRC is rising and is likely to continue to do so [4]. Understanding and identifying determinants of the outcome of CRC is therefore of increasing importance. While much literature focuses on the association between lifestyle factors and the incidence of $C R C$, there is little research on their association, with survival and recurrence [1]. The literature on recurrence is particularly limited due to difficulty obtaining a consistent definition of recurrence. Despite increasing attention in the literature to the role of lifestyle behaviour in the outcome of CRC, much research is inconclusive and contradictory, with studies repeatedly citing the need for further research $[5,6]$.

The aim of the present project was to investigate possible relationships between modifiable behavioural lifestyle factors and the long-term outcome in a cohort of CRC patients who underwent potentially curative surgery.

\section{Method}

\section{Study Population and Data Collection}

All patients, resident in the NHS Greater Glasgow \& Clyde (NHSGGC) area, diagnosed with colorectal cancer (ICD 10 code: C18-20) between 1st January 2011 and 31st December 2012, undergoing elective curative surgery were included [7]. Data were obtained from the West of Scotland Cancer Surveillance Unit, which holds Scottish Cancer Registry (SCR) data. SCR data are linked to National Records of Scotland (formerly General Register Office) death records and the last date of follow-up (date of censorship) was $30^{\text {th }}$ June 2015. Formal ethical approval for the study was not required as patients were not approached and only routinely collected data were used. 
A database was created to collate the required information. Age, sex, postcode, alcohol consumption, smoking, physical capacity, and body mass index (BMI) were obtained from the pre-operative assessment form on the NHS portal system. BMI was calculated from height and weight measured in the pre-operative assessment clinic using the formula weight/ (height) ${ }^{2}$ and other items were self-reported by patients. Cancer site, resection type, histopathological (Dukes) stage and surgical date were obtained from pathology and operation records.

\section{Exclusion Criteria}

Patients were excluded from the initial dataset if they were diagnosed with metastatic CRC ('Dukes D'), underwent emergency surgery, experienced an incomplete ( $R 1$ ) resection, had a polyp excised at colonoscopy, had multiple (synchronous) CRC tumours. Patients were also excluded if they did not have a pre-operative assessment form available within three months before surgery.

\section{Variables}

Cancers of the caecum to sigmoid colon were grouped as colonic cancers ( $\mathrm{C} 18)$ and cancers of the recto-sigmoid junction and rectum as rectal cancers (C19-20)[7]. Histopathological stage was obtained from SCR in the form of Dukes Stage (A-C2). Tumour site and stage were extracted from pathology and operation notes.

The patient's postcode was linked to the Scottish Index of Multiple Deprivation (SIMD) 2009 [9] to assess the deprivation of their area of residence. The index is based on seven weighted domains: income, employment, health, education, access to services, housing and crime rates. SIMD2009 is ranked into five quintiles with the numeral 1 representing the most deprived and 5 the least deprived [8]. 
Body Mass Index (BMI) was categorised as follows; <18.5 (underweight), 18.5-24.9 (healthy weight), 25-29.9 (overweight), 30-34.9 (obese I), 35-39.9 (obese II) and $\geq 40$ (obese III) [10]. Patients reported drinking alcohol or not and if so, how many units they consumed per week. A unit of alcohol is $10 \mathrm{~mL}$ of pure alcohol. The Scottish government's recommended limits were used as follows; females, $\leq 14$ units per week and males, $\leq 21$ units per week [11]. Smokers were classified as 'current smoker', 'ex-smoker' or 'non-smoker' and the number of cigarettes consumed per day was recorded. An ex-smoker was defined as one previously smoking but not currently. Physical capacity of patients was expressed as the ability to climb stairs and recorded in three levels as follows; 'climbs stairs without stopping', 'climbs stairs with stopping' or 'cannot climb stairs'.

\section{Statistical Analysis}

Tests of association were based on Pearson's Chi-squared test, the Chi-squared test for trend or Wilcoxon's paired test depending on parametric or non-parametric distribution of the data. Differences in survival were assessed graphically by Kaplan-Meier survival plots and then formally tested using the log-rank test. Cox proportional hazards model was used for multivariate analysis. The best model was assumed to be the one with the smallest value of the Akaike Information Criterion (AIC). Proportional hazards assumptions were assessed graphically using plots and were then formally tested using the PHTEST. All statistical analyses were carried out using STATA version 14. 


\section{Results}

\section{Clinicopathological data}

Of the initial 527 patients only 181 (34\%) satisfied all the inclusion criteria. Of those excluded 325 were due to no surgery being performed, two had only an R1 resection and a further 19 had no valid pre-operative form. There were 152 (46.8\%) deaths among the 325 non-surgical patients compared with $27(14.9 \%)$ deaths among the 181 in the surgical study group (Chi-squared test: $p<$ 0.001). Data were missing on Dukes stage (seven patients, smoking (one patient), alcohol consumption (three patients) and exercise capacity (two patients). These were not necessarily different individuals, but were all excluded from analysis because it was not possible to calculate the effect of each factor on survival.

Of the 181 patients, $114(63 \%)$ were male (Table 1$)$. The age of the study population was similar in males (68.7 (9.2) years) and females (67.0 (9.9) (Chi-squared test for trend: $p=0.14)$. The population was deprived with $78(43 \%)$ in the lowest SIMD quintile. There was no difference in deprivation by gender (Chi-squared test for trend: $p=0.25$ ).

Nineteen (10.6\%) patients reported being current smokers, 77 (42.8\%) were former smokers and $84(46.7 \%)$ had never smoked. Of 176 patients reporting the ability to climb stairs, 16 (91.5\%) reported being able to climb stairs without stopping, 10 (5.7\%) could not climb without a stop and $5(2.8 \%)$ could not climb stairs at all. Among the 179 patients with BMI data, 68 (38.0\%) were overweight and 67 (37.4\%) were obese. Of 174 patients with data on alcohol consumption, 82 (46.6\%) took none, $71(40.3 \%)$ did so within the guidelines and $23(13.0 \%)$ exceeded the recommended weekly limit. Females had a higher BMI than males $(p=0.004)$, but gender was not significantly associated with smoking $(0=0.54)$, exercise tolerance $(=0.17)$ or alcohol consumption $(P=0.08)$. 
Of the 181 patients, the cancer was in the colon in $129(71.3 \%)$ with $75(58 \%)$ being male and 54 (41.8\%) being female $(p=0.03)$. It was in the rectum in $52(28.7 \%)$ patients with a gender distribution of 39 [75\%] (male) and 13 [25\%] (female). Of the 174 having a Dukes stage classification, the stages were as follows: Dukes A 45 (25.9\%), Dukes B 77 (44.35) and Dukes C 52 (29.9\%) with no significant statistical difference according to gender $(p=0.78)$.

\section{Survival}

This cohort was followed up from date of surgery to death or $30^{\text {th }}$ June 2015 giving a total followup time of 480 person-years. During the period of follow up 27 deaths occurred, two within 30 days of surgery.

Of those studied, the only variables significantly affecting survival $(P<0.05)$ were age, $B M I$, Dukes stage and physical capacity (Table 2).

The best multivariate Cox proportional hazard model included only the same four variables (Table 3). Proportionality assumptions for the Cox model were tested and found to hold. Being over 70 years of age at diagnosis was independently associated with poorer survival compared with those younger (HR 2.74). Survival was significantly poorer among the 52 patients with a Dukes $C$ stage tumour than among the 122 patients with a Dukes stage A or B tumour (HR 6.32).

Overweight or obese patients had a poorer survival than those of normal weight (HR 2.81). The 15 patients who had difficulty in climbing stairs had a significantly poorer survival than the 161 who were able to climb stairs without stopping (HR 3.31).

\section{Discussion}

The aim of this project was to investigate possible relationships between modifiable behavioural factors and the outcome of patients undergoing curative surgery for CRC. The key statistically verified prognostic factors were age, Dukes stage, BMI and physical capacity. After adjustment, higher BMI (overweight and obese) (HR 2.81) and limited physical capacity (HR 3.31) were both associated with approximately a three-fold increase in mortality. The study also confirmed the 
well-known positive relationship between age and Dukes stage with survival $[12,13]$ with no significant associations with smoking or alcohol consumption.

The results suggest that being overweight or obese is associated with poorer survival, a finding consistent with previous literature $[6,14-16]$. Dignam et al reported that patients with a high BMI had a $28 \%$ increased risk of death from cancer (HR 1.28) than those with a normal BMI. Boyle et al found that overweight and obese women had almost twice the mortality of women with a normal BMI. Other studies have however demonstrated no association between BMI and survival after treatment for $\mathrm{CRC}[17,18]$, in some cases regarding $\mathrm{BMI}$ as an inappropriate measurement. We did not identify any underweight patients and therefore could not determine whether they too had a poorer outcome.

The relationship between poor physical capacity and lower survival may reflect patients' general wellbeing, in a similar way to the World Health Organisation Performance Status scale or it may be an indicatior of the degree of morbidity. There is evidence that Performance Status is an important predictor of the outcome of colorectal cancer, particularly when it is advanced. There is also evidence that patients who take exercise have between a $14 \%$ and $28 \%$ better survival than those who do not. Such results suggest that prehabilitation of patients with colorectal cancer before treatment may not only optimize peri-operative outcomes, but potentially improve the long-term outcomes also [19-21].

The study has several strengths. It is novel and uses up-to-date patient data. It is based on general questions at preoperative assessment and therefore no forward assumptions were made. The data were collected routinely as part of the hospital management of the patient, making the study simple to undertake. It also included all patients with non-metastatic colon and rectal cancer and addressed objective and subjective variables. Comparing the demographic and 
clinical characteristics of the included and excluded patients showed that the study was sufficiently representative of the total dataset, with only a slightly older mean age among the excluded patients. It may be that older patients were more likely to be unfit for surgery or to present with a synchronous tumour.

The study has several important limitations. Many studies of survival among patients with CRC have also shown a relationship between survival and age, gender and deprivation [23, 24]. The lack of significance of gender and deprivation in the present study is most likely due to the small sample size and the short duration of follow up. Another limitation is the potential information bias of self-reported information of behavioural factors. Other studies have used objective measures to reduce patient reported error, such as serum cotinine estimation to identify a smoker. As might be expected, there is evidence that self-reported smoking status is very accurate [25] but other data suggest that $20 \%$ of never-smokers underestimate their past environmental tobacco exposure [26]. The retrospective nature of the study may mean that the assessment of physical capacity is inaccurate when compared with those publications in the literature, which take detailed exercise history and categorise as in weekly MET hours or obtain information through accelerometers for example $[16,27]$ The increasingly topical question of the effect of diet on the outcome of outcome of CRC [1] is indicated by Meyerhardt et al who discovered that a western diet resulted in a worse recurrence-free and overall-survival [28]. Dietary information was not collected at the pre-operative assessment as it would have required a much more extensive form of data collection $[29,30]$.

The current study demonstrated the risk of low survival among overweight and obese patients. These might be helped by a weight loss programme such as BeWEL ${ }^{28}$, which might also reduce their risk of cardiovascular disease. Health-related behaviour may change after the diagnosis and 
treatment of malignancy and it would be useful to see from future research whether there is any change on repeated assessment following treatment.

In conclusion the study demonstrated a significant negative effect of physical capacity and increased BMI determined at the pre-operative assessment on survival after surgery for CRC. It did not, however, demonstrate an association between alcohol consumption or smoking with survival. It is uncertain whether changes in lifestyle behaviour improve the outcome of patients with surgically curable $C R C$, but there is good evidence that the burden of many other diseases and co-morbidity can be reduced through risk identification.

\section{References}

1. World Cancer Research Fund / American Institute for Cancer Research.Food, Nutrition, Physical Activity, and the Prevention of Cancer: a Global Perspective. Washington DC: AICR, 2007.

2. Cancer Research UK; Bowel cancer mortality Statistics Last updated: 22/01/2014. Accessed: 25/09/2015.

3. Haggar FA, Boushey RP. Colorectal cancer epidemiology: incidence, mortality, survival, and risk factors. Clin Colon Rectal Surg 2009; 22: 191-7.

4. NHS National Services Scotland. Information Services Division Scotland; Cancer Statistics: Colorectal Cancer 2010. Accessed on 03/04/2014.

5. Van Blarigan EL, Meyerhardt JA. Role of physical activity and diet after colorectal cancer diagnosis. J Clin Oncol 2015; 33: 1825-34.

6. Boyle T, Fritschi L, Platell C, Heyworth J. Lifestyle factors associated with survival after colorectal cancer diagnosis. Br J Cancer 2013; 109: 814-22.

7. International Statistical Classification of Diseases and Related Health Problems; 10th Revision. World Health Organisation, 2010. Accessed on 25/09/2015. 
8. Shafique K, Oliphant R, Morrison DS. The impact of socio-economic circumstances on overall and grade-specific prostate cancer incidence: a population-based study. Br J Cancer 2012; 107: 575-82.

9. The Scottish Government: Scottish Index of Multiple Deprivation: 2009 General Report. 2009. Accessed on 25/09/2015.

10. World Health Organisation: Global Database on Body Mass Index. 2006. Accessed on $25 / 09 / 2015$.

11. The Scottish Government: Alcohol. 2013. Accessed on 25/09/2015.

12. Manceau G, Karoui M, Werner A, Mortensen NJ, Hannoun L. Comparative outcomes of rectal cancer surgery between elderly and non-elderly patients: a systematic review. Lancet Oncol 2012; 13: E525-E36.

13. Cancer Research UK; Bowel cancer mortality Statistics. Last updated: 22/01/2014. Accessed: 25/09/2015.

14. Vrieling A, Kampman E. The role of body mass index, physical activity, and diet in colorectal cancer recurrence and survival: a review of the literature. Am J Clin Nutr 2010; 92: 471-90.

15. Dignam JJ, Polite BN, Yothers G, Raich P, Colangelo L, O'Connell MJ, et al. Body mass index and outcomes in patients who receive adjuvant chemotherapy for colon cancer. J Natl Cancer Inst 2006; 98: 1647-54.

16. Campbell PT, Patel AV, Newton CC, Jacobs EJ, Gapstur SM. Associations of recreational physical activity and leisure time spent sitting with colorectal cancer survival. J Clin Oncol 2013; 31: 876-85.

17. Haydon AM, Macinnis RJ, English DR, Giles GG. Effect of physical activity and body size on survival after diagnosis with colorectal cancer. Gut 2006; 55: 62-7. 
18. Kuiper JG, Phipps AL, Neuhouser ML, Chlebowski RT, Thomson CA, Irwin ML, et al. Recreational physical activity, body mass index and survival in women with colorectal cancer. Cancer Causes Control 2012; 23: 1939-48.

19. Holmes MD, Chen WY, Feskanich D, Kroenke CH, Colditz GA. Physical activity and survival after breast cancer diagnosis. JAMA 2005; 293: 2479-86.

20. Courneya KS, Friedenreich CM, Quinney HA, Fields ALA, Jones LW, Fairey AS. A randomized trial of exercise and quality of life in colorectal cancer survivors. Eur J Cancer Care 2003; 12: 347-57.

21. Courneya KS, Katzmarzyk PT, Bacon E. Physical activity and obesity in Canadian cancer survivors: population-based estimates from the 2005 Canadian Community Health Survey. Cancer 2008; 112: 2475-82.

22. Brown L, Christie S, Gill V, Gray L, et al (2015) The Scottish Health Survey; 2014 edition. A National Statistics Publication for Scotland. The Scottish Government. http://www.gov.scot/Resource/0048/00485587.pdf Accessed on:25/09/2015.

23. Morrison DS, Batty GD, Kivimaki M, Davey Smith G, Marmot M, Shipley M. Risk factors for colonic and rectal cancer mortality: evidence from 40 years' follow-up in the Whitehall I study. J Epidemiol Community Health 2011; 65: 1053-8.

24. Oliphant R, Nicholson GA, Horgan PG, Molloy RG, McMillan DC, Morrison DS, et al. Deprivation and Colorectal Cancer Surgery: Longer-Term Survival Inequalities are Due to Differential Postoperative Mortality Between Socioeconomic Groups. Ann Surg Oncol 2013; 20: 2132-9.

25. Vartiainen E, Seppala T, Lillsunde P, Puska P. Validation of self reported smoking by serum cotinine measurement in a community-based study. J Epidemiol Community Health 2002; 56: 167-70. 
26. Martinez ME, Reid M, Jiang RY, Einspahr J, Alberts DS. Accuracy of self-reported smoking status among participants in a chemoprevention trial. Prev Med 2004; 38: 492-7.

27. Meyerhardt JA, Giovannucci EL, Holmes MD, Chan AT, Chan JA, Colditz GA, et al. Physical activity and survival after colorectal cancer diagnosis. J Clin Oncol 2006; 24: $3527-34$.

28. Meyerhardt JA, Niedzwiecki D, Hollis D, Saltz LB, Hu FB, Mayer RJ, et al. Association of dietary patterns with cancer recurrence and survival in patients with stage III colon cancer. JAMA 2007; 298: 754-64.

29. Anderson AS, Craigie AM, Caswell S, Treweek S, Stead M, Macleod M, et al. The impact of a bodyweight and physical activity intervention (BeWEL) initiated through a national colorectal cancer screening programme: randomised controlled trial. Bmj-Brit Med J 2014; 348

30. Hubbard G, Brown A, Campbell A, Campbell N, Diament B, Fielding S, et al. Do health behaviours change after colonoscopy? A prospective cohort study on diet, alcohol, physical activity and smoking among patients and their partners. BMJ Open 2014; 4: e003706. 
Table 1. Baseline socio-demographic, behavioural and tumour characteristics of 181 patients with Colorectal Cancer (CRC) by gender.

\begin{tabular}{|c|c|c|c|}
\hline & male & female & total \\
\hline & $\mathrm{N} \%$ & $\mathrm{~N} \%$ & $\mathrm{~N} \%$ \\
\hline \multicolumn{4}{|l|}{ Age group } \\
\hline$<=59$ yrs & $18(15.8 \%)$ & $16(23.9 \%)$ & $34(18.8 \%)$ \\
\hline $60-69$ yrs & $37(32.5 \%)$ & $23(34.3 \%)$ & $60(33.1 \%)$ \\
\hline $70-79$ yrs & $46(40.4 \%)$ & $22(32.84 \%)$ & $68(37.6 \%)$ \\
\hline$>=80 \mathrm{yrs}$ & $13(11.4 \%)$ & $6(9.0 \%)$ & $19(10.5 \%)$ \\
\hline \multicolumn{4}{|l|}{ Deprivation } \\
\hline 1. most deprived & $45(39.5 \%)$ & $33(49.3 \%)$ & $78(43.01 \%)$ \\
\hline 2 & $20(17.5 \%)$ & $10(14.9 \%)$ & $30(16.6 \%)$ \\
\hline 3 & $8(7.0 \%)$ & $5(7.5 \%)$ & $13(7.2 \%)$ \\
\hline 4 & $16(14.0 \%)$ & $6(9.0 \%)$ & $22(12.2 \%)$ \\
\hline 5. least deprived & $25(21.9 \%)$ & $13(19.4 \%)$ & $38(21.0 \%)$ \\
\hline \multicolumn{4}{|l|}{ Smoking } \\
\hline Current & $10(8.9 \%)$ & $9(13.4 \%)$ & $19(10.6 \%)$ \\
\hline Never & $54(47.8 \%)$ & $30(44.8 \%)$ & $84(46.7 \%)$ \\
\hline Former & $49(43.4 \%)$ & $28(41.8 \%)$ & $77(42.8 \%)$ \\
\hline \multicolumn{4}{|l|}{ Fitness } \\
\hline cannot climb stairs & $5(4.6 \%)$ & $0(0 \%)$ & $5(2.8 \%)$ \\
\hline Climb stairs with stopping & $6(5.5 \%)$ & $4(6.1 \%)$ & $10(5.7 \%)$ \\
\hline Climb stairs without stopping & $99(90.0 \%)$ & $62(93.9 \%)$ & $161(91.5 \%)$ \\
\hline
\end{tabular}




\begin{tabular}{|c|c|c|c|}
\hline BMI & & & \\
\hline $18.5-25$ Normal & $32(28.6 \%)$ & $12(17.9 \%)$ & $44(24.6 \%)$ \\
\hline 25-29 Overweight & $44(39.3 \%)$ & $24(35.8 \%)$ & 68 (38.0\%) \\
\hline 30-34 Class I & $29(25.9 \%)$ & $17(25.4 \%)$ & $46(25.7 \%)$ \\
\hline 35-39 Class II & $5(4.5 \%)$ & $7(10.5 \%)$ & $12(6.7 \%)$ \\
\hline$>=40$ Class III & $2(1.8 \%)$ & $7(10.5 \%)$ & $9(5.0 \%)$ \\
\hline Alcohol consumpt & & & \\
\hline None & $44(40.0 \%)$ & $38(57.6 \%)$ & 82 (46.6\%) \\
\hline within guidance & $51(46.4 \%)$ & $20(30.3 \%)$ & $71(40.3 \%)$ \\
\hline above guidance & 15 (13.6\%) & 8 (12.1\%) & $23(13.1 \%)$ \\
\hline Location of tumou & & & \\
\hline Colon & 75 (65.8\%) & $54(80.6 \%)$ & $129(71.3 \%)$ \\
\hline Rectal & $39(34.2 \%)$ & $13(19.4 \%)$ & $52(28.7 \%)$ \\
\hline Dukes stage & & & \\
\hline A & $30(27.8 \%)$ & $15(22.7 \%)$ & $45(25.9 \%)$ \\
\hline$B$ & $45(41.7 \%)$ & $32(48.5 \%)$ & $77(44.3 \%)$ \\
\hline$C$ & $2(1.9 \%)$ & $1(1.5 \%)$ & $3(1.7 \%)$ \\
\hline $\mathrm{C} 1$ & $25(23.2 \%)$ & $18(27.3 \%)$ & $43(24.7 \%)$ \\
\hline $\mathrm{C} 2$ & $6(5.6 \%)$ & $0 \quad(0 \%)$ & $6(3.5 \%)$ \\
\hline
\end{tabular}


Table 2. Hazard Ratios (HR) and $95 \%$ Confidence Intervals (Cl) of potential factors relating to allcause mortality of 181 patients having surgery for colorectal cancer (CRC).

\begin{tabular}{|c|c|c|c|c|c|}
\hline & & $\mathrm{N}$ & Log rank test $p$-value & $\mathrm{HR} \pm 95 \% \mathrm{Cl}$ & $\mathrm{P}(\mathrm{PH})^{*}$ \\
\hline \multirow[t]{2}{*}{ Age } & under 70 & 8 & & 1 & \\
\hline & 70 or over & 19 & 0.013 & $2.72(1.19,6.21)$ & 0.90 \\
\hline \multirow[t]{2}{*}{ Gender } & male & 20 & & 1 & \\
\hline & female & 7 & 0.13 & $0.52(0.22,1.24)$ & 0.43 \\
\hline \multirow[t]{2}{*}{ SIMD } & most deprived $1 \& 2$ & 16 & & 1 & \\
\hline & $3-5$ & 11 & 0.97 & $0.98(0.46,2.12)$ & 0.96 \\
\hline \multirow[t]{2}{*}{ Site } & colon & 20 & & 1 & \\
\hline & rectal & 7 & 0.89 & $0.94(0.39,2.23)$ & 0.33 \\
\hline \multirow[t]{2}{*}{$\begin{array}{l}\text { Dukes } \\
\text { Stage }\end{array}$} & Stage A-B & 10 & & 1 & \\
\hline & Stage C & 17 & $<0.001$ & $4.4(2.02,9.65)$ & 0.51 \\
\hline \multirow[t]{2}{*}{ BMI } & normal & 12 & & 1 & \\
\hline & overweight/obese & 14 & 0.006 & $2.8(1.29,6.06)$ & 0.16 \\
\hline \multirow[t]{2}{*}{ Smoking } & smoking never & 12 & & 1 & \\
\hline & ever & 15 & 0.89 & $1.05(0.49,2.25)$ & 0.63 \\
\hline \multirow[t]{2}{*}{ Alcohol } & none & 12 & & 1 & \\
\hline & any & 14 & 0.91 & $1.05(0.48,2.27)$ & 0.87 \\
\hline \multirow[t]{2}{*}{ Exercise } & $\begin{array}{l}\text { no problem with } \\
\text { stairs }\end{array}$ & 20 & & 1 & \\
\hline & problem with stairs & 5 & 0.02 & $2.95(1.1,7.87)$ & 0.36 \\
\hline
\end{tabular}


- $\quad$-value of proportional hazards; $\mathrm{P}(\mathrm{PH})$ is the $\mathrm{p}$-value associated with the formal test of the proportionality of the hazards.

$\mathrm{BMI}=$ body mass index,

SIMD = Scottish Index of Multiple Deprivation

Table 3 Hazard Ratios (HR) and 95\% Confidence Intervals (Cl) of adjusted all-cause mortality of 181 patients having surgery for colorectal cancer (CRC).

\begin{tabular}{|c|c|c|c|c|}
\hline & & P-value & $\mathrm{Hr} 95 \% \mathrm{Cl}$ & $\mathrm{P}(\mathrm{PH})^{*}$ \\
\hline \multirow[t]{2}{*}{$\begin{array}{l}\text { Age } \\
\text { years }\end{array}$} & under 70 & & 1 & \\
\hline & 70 or over & 0.032 & $2.74(1.09,6.88)$ & 0.72 \\
\hline \multirow[t]{2}{*}{$\begin{array}{l}\text { Dukes } \\
\text { Stage }\end{array}$} & Stage A,B & & 1 & \\
\hline & Stage C & $<0.001$ & $6.32(2.69,14.8)$ & 0.17 \\
\hline \multirow[t]{2}{*}{ BMI } & normal & & 1 & \\
\hline & Overweight/ obese & 0.013 & $2.81(1.24,6.35)$ & 0.19 \\
\hline \multirow[t]{2}{*}{ Exercise } & $\begin{array}{l}\text { able to climb stairs } \\
\text { without testing }\end{array}$ & & 1 & \\
\hline & $\begin{array}{l}\text { unable to stairs } \\
\text { without resting }\end{array}$ & 0.03 & $3.31(1.13,9.66)$ & 0.44 \\
\hline
\end{tabular}

* p-value of proportional hazards; $\mathrm{P}(\mathrm{PH})$ is the $\mathrm{P}_{-}$value associated with the formal test of the proportionality of the hazards. 